\title{
Shared Living, Experiences, and Intimacy over Video Chat in Long Distance Relationships
}

\author{
Saul Greenberg \\ University of Calgary, Canada \\ Carman Neustaedter \\ Simon Fraser University, Canada
}

\begin{abstract}
Many couples live a portion of their lives being separated from each other as part of a long-distance relationship. This includes a large number of dating college students as well as established couples who are geographicallyseparated because of situational demands such as work. Long distance couples often face challenges in maintaining some semblance of intimacy given the physical distance between them. Traditional media helped here, where they would stay connected by physical letters, telephones, e-mail, texting, and instant messaging. More recently, many couples resort to "hanging out" over the new generation of video chat systems in order to stay connected. We explore this phenomenon by presenting case studies of how couples in long distance relationships hang out over video. Each couple is in a unique relationship situation, yet all share increased intimacy over distance by leaving a video link going between their residences for extended periods of time. These episodes involve couples participating in activities that are sometimes shared and sometimes not, where the key component is simply feeling the presence and involvement of the remote partner in day to day life.
\end{abstract}

\section{Introduction}

Long distance relationships (LDRs) are a common reality in this day and age. LDRs include not only people who are geographically separated by large distances, but also those who may be geographically close but who live in different residences. Both share similarities in that access for day-to-day communication is limited. LDRs also include couples at different stages of relationships: from recentlyintroduced dating couples, to established couples including partners and those who are married. There is a rich literature on the nuances of such LDRs, ranging from

\footnotetext{
Greenberg, S. and Neustaedter, C. (2011)

Shared Living, Experiences, and Intimacy over Video Chat in Long Distance Relationships. Research report 2011-1005-17, Department of Computer Science, University of Calgary, Calgary, Alberta, Canada, July.
} 
academic studies to popular culture "how to" sites that offer advice and experiences to couples.

What is perhaps surprising is that LDRs where people live apart for significant periods of time are not exceptional. Consider dating college students, who often live apart in different cities. Some estimates suggest about $75 \%$ of college students have been involved in a LDR, and that from $25-50 \%$ of students are currently involved in an LDR (Stafford, 1990, 2005). In another study, 43.6\% of university students reported being in a long distance relationship at some point (Rumbough, 2001). Established partners may also find themselves in an LDR (Stafford, 2005). Work may force a married or domestic partners to live apart for a while. For example, this may result from the assignment of one person to a distant work location or a "two-body problem" where partners cannot find work in the same city (Aguila, 2009). Certain jobs often require people to live in different places or to travel for long durations, such as in professional athletics, the military, offshore oil workers, people who do extensive work in the field, one partner attending an educational institute elsewhere, or mariners who are off at sea. Other non-work factors may come into play (Stafford, 2005). Incarceration separates people. Separation may be voluntary, such as dual-career and dual-residence couples who choose to live separately due to career demands, desires for autonomy, and/or desires to live geographically close to family. Crisis (such as ailing parents) may force one person to temporarily reside elsewhere. When taken collectively, we see that LDRs are not rarities. Rather, a good percentage of the population is or has been in a significant LDR (Stafford, 2005). For some people, LDRs are highly enjoyable for they provide partners with increased degrees of autonomy along with feelings of novelty (Stafford, 2005).

Couples in LDRs naturally turn to technology as a tool to mediate their relationship over distance. Historically, they have appropriated non-digital communications technologies to do so, including letter writing and phoning. As digital media and interconnectivity became widespread, they then appropriated emailing, texting, and instant messaging. More recently, free video conferencing software and inexpensive webcams have become available. Consequently, we now see couples adopting and using video chat systems like Skype, Google Chat, Apple FaceTime, or iChat. The general question is: how do LDRs use this new videobased medium?

Specifically, the focus of our chapter is presenting how partners in long distance relationships use video chat systems to maintain intimacy in their relationships. In particular, we examine in-depth instances where a video link is used for long durations of time, i.e., where partners "hang out" together over the link. This goes beyond the more simple phone call-like uses of video chat, where we explore how partners integrate video connections as a core part of their communication routine for extended periods of time in order to enhance intimacy. 
We conducted interviews with fourteen individuals in serious long distance relationships. For this chapter, we explore and detail two composites from these interviews as case studies: a geographically-close relationship between two adjacent cities, and a geographically-far relationship between two countries. As we will see, in both cases video is used in a very similar manner, despite the difference in distance and varying relationship dynamics generated as a result.

The main message of these two case studies - and of our chapter - is that LDR couples leave video links on for long periods of time primarily because it provides them with increased intimacy regardless of the relationship situation. This intimacy stems from an increased feeling of presence and involvement in each other's lives.

We begin by describing related work on long distance relationship maintenance. Next, we outline our interview methodology from which our case studies are drawn. Subsequently, we articulate the details of each case study relationship and how video is used to maintain intimacy for the partners, as well as deviations of individuals from our composites

\section{Related Work}

In all relationships, people perform actions and participate in activities that help to sustain their desired relationships - what is sometimes called relationship maintenance strategies (Stafford and Canary, 1991, Canary and Stafford, 1994, Stafford, 2005). These include strategic activities that people purposely do to help maintain their relationship (e.g., talking politely) as well as routine behaviors that are simply a part of everyday activities (e.g., cleaning dishes) (Canary and Stafford, 1994, Dindia and Emmers-Sommers, 2006). Some of the most common interactive activities include acting cheerful and polite, talking openly about the relationship, providing assurances that the relationship has a future, expressing one's love through physical acts, and managing conflicts (Canary and Stafford, 1994). We also see maintenance strategies relate to how one spends his or her time. This most often includes interacting as a couple with other friends or family who support the relationship, and performing one's share of household tasks or chores. Studies have shown that relationships will deteriorate without the use of a combination of the above behaviors and activities (Canary and Stafford, 1994).

When it comes to LDRs, the same basic relationship maintenance strategies are used, with the exception of "shared tasks" (e.g., cleaning) since it is harder to perform these over distance (Pistole et al., 2010a). Partners also need to invest in the relationship in various additional ways such as traveling, being available for communication, and financially supporting one's partner, if needed (Pistole et al., 2010b). 
Researchers sometimes try to gauge relationship satisfaction, where measures are commonly based on satisfaction with several attributes such as one's influence in the relationship, sexual activities, one's own leisure time, division of household tasks, time together, finances, and, most importantly, communication (Vangelisti and Huston, 1994). One could argue that LDR partners suffer here. They find it harder to communicate, have fewer sexual activities, less time together and so on, simply because they are not able to see and interact in person as often. If correct, this could cause a lower degree of satisfaction in LDRs. This premise is why many believe that proximity and co-residency is necessary for a satisfactory relationship. However, research has challenged the assumption that proximity is necessary (Stafford and Reske, 1990, Stafford, 2005). LDRs can be satisfactory because people find ways to achieve the previously mentioned relationship behaviors in spite of being separated by distance (Stafford and Reske, 1990, Stafford, 2005). This is not just an academic argument but one also seen in fact: many LDRs flourish in day to day life.

In terms of supporting communication within an LDR, digital media-as realized over the Internet and cellular network-is a potential game-changer. In the past, one defining characteristic of an LDR is that communication opportunities are limited (Stafford, 2005). Yet the low cost and ubiquity of digital communication tools seemingly lessens this limitation. Traditional digital media-email, chat rooms, instant messaging, cell phone calls, SMS, texting, and social network sites-creates easier and richer ways for LDR partners to communicate not only with each other but with their common social network. Studies have shown that such digital communication media can ease loneliness and increase feelings of closeness (Aguila, 2009) and also increase relationship satisfaction, trust, and commitment while lowering jealousy (Dainton and Aylor, 2002). Media is now increasingly rich, and multiple channels provide support for a range of communicative activities - assurance, openness, positivity, and discussing social networks (Johnson et al., 2008, Stafford, 2005) - and even intimate activities like cybersex (Rumbough, 2001). Novel research prototypes are even being designed to specifically target couples and the need to maintain their relationships over distance. For example, couples can now share melodies over their cell phones (Shirazi et al., 2009), click to say, "I love you" (Kaye, 2006), or - at the extremes - physically based cybersex via robotic sex toys (Rheingold, 2005). However, such technologies are not without their challenges. Scheduling times for communication over such channels is not always an easy task (Aguila, 2009) and is certainly more problematic than "bumping into" one's partner while at home. Many communication channels are also not very rich when compared to face-to-face situations.

Within the last few years, a new digital medium has entered the scene: video chat systems that run over the Internet. While video has been available earlier, it often required technical knowledge to use and set it up, it was costly if purchased as a robust product, or it was unreliable and low quality if free. The recent generations of Skype (www.skype.com) and other video-based instant messengers have 
changed this: most computer-literate people can install and use it as a reasonably reliable free service.

Our research question asks: Why and how do people in LDRs use video chat systems? How do they use them in ways that go beyond simple phone call-like conversations, particularly those situations where partners use video over extended periods of time? In particular, does the richer communication channel afforded by "always-on" video better support relationship maintenance over distance? The answers to these questions are the focus of our chapter.

\section{Case Study Methodology}

We conducted semi-structured interviews with fourteen individuals (half female) in long distance relationships. In one instance we interviewed both partners from the same couple. Six interviews were conducted over Skype and the remaining eight were performed in person at either of the researchers' offices. All interviewees were in serious relationships that had moved beyond mere dating, where they considered each other as partners (albeit to a varying degree). Thus, they are couples where each partner would certainly consider the other to be "family." Participants' ages varied from 19 years to their mid-30s. The geographical distance between partners also varied heavily. The closest couple lived in the same city. The furthest apart had partners on the other side of the world, where they were separated not only by distance but by large time zone differences of 10-12 hours.

Our sampling is targeted, and we make no claim that it represents a snapshot of the general population as a whole. First, our recruitment process favored calls to the University community; thus our sample tended to have one of the partners being an undergraduate or graduate student, a researcher, or a professor, although it also included blue-collar workers. Even so, the occupations of their partners varied quite heavily. Second, we intentionally restricted our LDR recruitment to those who already used video as one of the primary technologies for communicating with their distant partner, preferably where they kept a video link going with their partner for extended periods of time. Third, we wanted people who had established relationships $v s$. those who had just met and were still in a very tentative stage (e.g., Internet dating). Still, we tried to stay somewhat general, as we did not select for a particular kind of LDR relationship dynamic. This meant that our sample included quite a few different kinds of relationships in terms of their length, commitment, and relationship dynamics.

What we found remarkable with all of these couples was that each, regardless of the relationship dynamics, was able to maintain large degrees of intimacy through their LDR because the video channel afforded unique opportunities to connect the partners' physical locations and created a shared sense of presence be- 
tween the partners. In the following sections, we describe the routines of partners in two types of relationships - short and long distance - as case studies that highlight this phenomenon. Our case studies were selected in order to emphasize both the diversity of couples' relationship situations and the commonality of how they all used video.

Each case study presents the relationship of one couple and their communication routines surrounding the use of video, where each couple is an aggregate of several participants. This was necessary as presenting the results from a single couple in detail risks identifying them and breaching ethical guidelines for the research. Naturally, the aggregation that we have done risks "averaging" the details of our participants' relationships and removing any idiosyncrasies. To circumvent this, after presenting the case studies, we discuss any notable differences that we saw between participants. It is also important to recognize that the case studies we present are not personas (Cooper, 1999, Grudin and Pruitt, 2002); instead, they are factual details about our participants, despite being aggregates. All quotes were also told directly to us.

\section{Case Study One: Connecting Between Cities}

Kaitlyn is 25 years old and has been dating her partner, Tyler, aged 26, for nearly seven years. Currently, Tyler is a software engineer, while Kaitlyn is a graduate student. Kaitlyn and Tyler lived together for about two years before she decided she wanted to return to school to pursue a graduate degree. After carefully talking this through and the effect that it would have on their relationship, Kaitlyn decided to move with a mixture of hesitation and excitement; she was excited to pursue more schooling but would miss being around Tyler day-in and day-out, even though they expected to spend major holidays and the summer months together. They also decided that once Kaitlyn had finished school and was able to move back in with Tyler that the two of them would get married.

Kaitlyn now lives approximately a two-hour drive from Tyler on the east coast of the United States. Kaitlyn and Tyler have been living apart for six months and see each other typically once every other weekend, but this depends on how their schedules permit. Because she is a student, Kaitlyn's schedule is somewhat more flexible than Tyler's so she is the one that travels to Tyler's place so that they can be together (although sometimes they meet halfway in a city between them). When her school workload is light, she can usually leave from school early Friday afternoons and beat rush hour traffic on her way out of town to travel to see Tyler. Visits to see Tyler focus on him at the expense of Kaitlyn's other friends and family who also live in the same city as Tyler. Kaitlyn feels this is unfortunate, but when she visits, she really does want to see Tyler the most and her visits are 
for such a short amount of time (e.g., two days on the weekend) that there really isn't time to see other people.

Kaitlyn was quite satisfied with her relationship with Tyler prior to moving, and this has carried over into their long-distance relationship. She feels that because they have been together for so long, they don't need to say much to each other to communicate. They just need to be together.

When Kaitlyn and Tyler are not visiting each other, Skype plays a critical role in maintaining their typical relationship activities. When Kaitlyn first moved, she started using Skype to call Tyler because she didn't want to have to pay for a landline phone. This use quickly extended to having long video sessions with Tyler where they frequently "hang out" together.

They've developed a routine around this. Each weekday, Tyler arrives home from work between 5 and 5:30pm. He phones Kaitlyn around 7pm, as this is usually when she arrives at her home after work. The call is usually just to coordinate getting onto Skype. If she is ready, the two will start a video chat session on it. The phone call beforehand allows both to stay offline in Skype and only come online to video call each other. They do this because Kaitlyn would prefer to stay offline until Tyler is available, as her mother tends to call at inopportune times.

Kaitlyn and Tyler usually keep their video link going for the remainder of their evening until bedtime, about four hours, to enhance what Kaitlyn calls "shared living" even though apart. During this time, they will most often be "doing their own thing" around the house, while occasionally looking at and chatting with each other through the link. Kaitlyn might make herself dinner, eat, clean the house, do laundry, or sit down to watch some television. Tyler, on the other hand, has usually already eaten by the time Kaitlyn gets home so he will be watching television, playing video games, or sometimes even doing some additional work from home.

"Usually he's sitting on the couch and eating some kind of snack and catching up on, you know, TV...And if there's something that we need to say to each other we'll chime in every now and then...Typically it's a 'we keep it running and live our lives' kind of deal. And it's typical evening stuff, making dinner, making sure things are cleaned up, getting things ready, taking care of personal business, stuff like that. We use video as a method to simulate shared living. Even if we aren't talking, the video channel is open...We do the things we would normally do if we were together and can see one another doing it."

As the quote shows, Tyler sets his laptop on a coffee table in front of his couch so that Kaitlyn can see him most of the time; she doesn't watch him constantly, but will occasionally glance at the Skype window to see what Tyler is doing. Kaitlyn will typically move her laptop between the kitchen and living room, depending on where she is, to keep him in sight. Later in the evening, once she gets tired, she will tell Tyler that she is about to go to bed and the two will end the Skype session. 
They also show off new things that have happened to them. For example, when Tyler gets a haircut, he shows it to her. Kaitlyn also shows off the new things she has bought, like clothes and new glasses.

Their routine is fairly static for the couple and they will do it day-in and-day out. They love spending time together and the video link provides them with an important opportunity to do this over distance.

Kaitlyn and Tyler also use Skype for conversations more akin to phone calls. However, they stress that it is not just a phone call.

"Its really hard to know over the phone to know what's happening in your partner's life. For those reasons seeing someone's body language... its easier to get in there and be closer. ... The voice is not enough. The relationship is so physical and visual. Its not just about hearing and talking."

When they do talk, both find it important to be able to see each other, to see each other's reactions, to get a sense of how they are generally feeling, whether they are tired, and so on.

"If you asked 'how was your day' over the phone its pretty uneventful. Like if you do it on Skype and actually see the body language the expressions and all that its pretty good."

Both comment that Skype adds a dimension of empathy not available on the phone, as they can tell how a person is doing from their appearance, facial expressions, and body language. As Tyler says:

“I think it just comes down to seeing the person's eyes and smile ... sometimes I see her in pretty rough shape on Skype, terrible, like she didn't sleep for a couple of days, overworked, and almost depressed... Its definitely something I cannot catch by phone. I just won't realize what she is going through or whatever, and she'll tell you 'I'm really tired' and all that', but what does that mean? But when I see her like that... her crazy hair and the crazy eyes, well, you can try to be more understanding... at least you know about it. I can do a bit more about it to help, or to say something encouraging."

For them, video also removes a lot of misunderstandings that might otherwise occur over the phone because they can now see each other's facial expressions. Tyler comments:

"I always apparently sound pretty harsh when I'm talking or kinda like even when I'm joking it doesn't sound like I'm joking...I would sometimes upset her [on the phone] without even knowing I upset her and of course without intending...With video the problem I had on the phone goes away because she can see that I'm smiling, she can see that I'm being supportive, she can see that I'm not frowning or being angry at her, so you know in that kind of sense it removed those obstacles for us." 
Conversations between Kaitlyn and Tyler will happen when the need arises and more often than not they will happen at the onset of their evening together, or just before Kaitlyn heads to bed. Here they discuss their day-to-day activities, their biggest worries, plans for seeing each other, and sometimes they will even complain about things or argue. In fact, when they argue, they prefer to do it over Skype so they can see the other person's facial expressions.

"Even when we fight we prefer to fight online and see each other because we can see the facial expression of the other person...I think in some cases it can make it worse. In some cases, it can soften it, depending on our reactions really. If say I get so upset I'm bursting into tears, he calms down. Or if something is happening and I'm getting really angry and I'm just ignoring him, he gets more angry so really it depends on the reactions of the person. But the good thing about it is you can see the other person's facial expression because it gives you an idea of what the person is feeling at that moment. If we want to hurt each other more we can, if we want to calm down more we can. It gives us that ability."

Kaitlyn and Tyler also share experiences, such as dinner and television. On some occasions, Kaitlyn and Tyler will spend their time together by having shared dinners, where they plan to both have the same meal and sit down together while they eat. Here Kaitlyn and Tyler do not think of their dinner as a video "date"; to them, it is just a normal evening together, much like a couple living together might spend the evening at home together.

"We started having dinner, which has been nice...it'll be a sushi night and we'll get sushi and ahh, umm, so yah, as much as we can to sort of normalize this ridiculous long distance relationship we try...In a way we both know that it's not a date, it's just we're having dinner together in front of Skype. Because it's not a date and I think we're just so used it being casual."

Both like to watch a lot of television and their favorite shows are reality TV ones. Occasionally, they will both plan to watch a show together because they love to see each other's reaction to the sometimes "over the top" antics of the contestants. They also tend to talk a lot as the show airs, and they both enjoy hearing each other's commentary. What makes this routine work well is that they are in the same time zone so the television shows are available at the same time for both of them.

"The reason why we watch together is to see and hear each other's reactions for the shows that we like so much...When we were in [living] together, it was like constant conversation and making jokes and laughing about stupid things people say...it's more like a tool to get to know each other."

While Kaitlyn and Tyler consider everything they do over the link as being intimate, they also do more explicit intimate acts via video. They often 'touch' and 'hug' each other, usually when they have eye contact. Tyler touches by moving his hand close to the camera and doing a stroking gesture (as if touching the other 
person's face). Kaitlyn hugs Tyler by wrapping her arms around her body in an embrace, and Tyler typically returns the gesture. Kaitlyn will routinely blow kisses to Tyler, especially before falling asleep. He similarly blows them back, but finds it more funny than serious.

They have also tried "cybersex" over the video link but found it less than satisfying. Both found cybersex over video awkward. In spite of being sexually active when physically together, both felt shy in having the other person "watch them." They have now agreed to save their sexual activities for the times they are able to meet up in person. Yet Kaitlyn still occasionally flirts with Tyler to try and entice him for their next visit. Here she will partially unclothe herself and show Tyler, and Tyler would respond with a smile, or a kiss, or a hug.

"But I did like to just strip tease and have this fun with the video and just showing parts of clothing or parts of skin. Like playing with the frame... I'd step away and just show my bra...or showing my back so not really showing everything but still teasing."

Taken together, we can see from the above case study that a video link plays a critical role in allowing Kaitlyn and Tyler to share time together when they are apart. The link is about shared living, shared experiences, and shared intimacy.

Leaving the video link open means that they can share an evening together just like they normally do when visiting each other, and like they did before Kaitlyn moved away. It is the presence of each other for these activities that is most important for the two of them, and it is the closest they can get to their normal evening routine while apart. They certainly also use other technologies to connect like text messaging and email, but they are not able to share their time together or feel the other person's presence with these tools. Thus, the video link provides an increased feeling of intimacy between the two partners simply by allowing them to share time together. They stress video is a major contributor to their success. When asked what would happen if Skype wasn't available, they said:

"It would have a big effect. You lose that intimacy. ... It's definitely intimacy, all those small things. That's basically all [Skype] is about. And if you don't have Skype, it would be a big deal."

Despite their successes, there are lots of opportunities for systems to be designed to support their activities better. When directly conversing, mutual eye contact and gaze is certainly challenging for Kaitlyn and Tyler. They also routinely face audio problems. When they are watching TV together, Skype picks up the sound of Kaitlyn and Tyler's voices in addition to the sound coming from both of their TVs. This makes it difficult to hear and can duplicate the TV show's sound. Lighting can also be an issue depending on where Kaitlyn and Tyler place their laptops in the home (e.g., a dimly lit living room is nowhere near as bright as a well-lit office). Sometimes moving the laptop can be quite challenging, given its weight and the wear of the battery (and its inability to last a long time), and the 
(lack of) space where Kaitlyn needs to set it in some rooms (e.g., small counters in the kitchen). The connection sometimes fails, or the video quality degrades due to Internet load. However, despite these challenges, Skype allows Kaitlyn and Tyler to do things together that would not be possible without the video link.

\section{Case Study Two: Connecting Between Countries}

May-ling is 31 years old and lives in a major metropolitan city in Canada. Her boyfriend, Ming, aged 34, lives in China and works at a marketing company where he often works from home. May-ling met Ming five years ago when she was living in China. About two years into their friendship, she started dating Ming. Several months after this, May-ling received a job offer in Canada as an architect. This was a good career move so she took it. She moved to Canada and continued to date Ming. About two years into their LDR, May-ling and Ming were engaged to be married. They plan to get married within the next year and Ming is actively looking for a job in the same city as May-ling in Canada. Once he has work, he will move to be with her.

May-ling and Ming see each other in person only twice a year. May-ling has family in China and so it makes sense for her to visit Ming there; he has no other relations in Canada. May-ling typically travels to China over the "Christmas holiday" break and then once in the summer time when she takes vacation days. She will spend two weeks with Ming, but a small portion of this time is also shared with May-ling's parents who live in a city that is a short two-hour drive away from Ming's home. May-ling really enjoys visiting Ming in person, however, because they only see each other twice a year, the time they do spend together can be overwhelming. They simply aren't used to being physically around each other day-in and day-out.

Their use of a video-based system such as Skype started during this separation out of necessity. While Ming had a webcam, May-ling didn't. Nor had she used Skype regularly.

"It was two days after I [arrived] here, and I didn't have a camera. In those two days it was very difficult for me. Although we spoke by cell phone and home telephone, it was very difficult for me not seeing him. So I [went] and bought a camera, a web cam. ... he already had one, but I didn't."

When they are apart, May-ling and Ming make heavy use of text messaging. They exchange messages sporadically throughout the day, such as good morning greetings, "I love you" notes, and short answers to questions. When they need to have more detailed conversations or to just see one another, they would call each other over Skype. This happens at both work and home. May-ling and Ming talk 
about their day-to-day activities and the video feed helps to show the other person, which moves it beyond a phone-call like conversation.

"[Video] just makes talking more pleasant and you can see facial expressions. I think that's a really important that you miss when you're chatting or talking on the phone... I could not stand not seeing [him]. I mean, I needed him, I needed to see him, and actually everyday we also talk by our cell phone but its not enough for us. I need to see his face. And he also has the same feeling."

As with Kaitlin and Tyler, intimacy and empathy matters.

"We used very lovely words to each other. I always expressed/stated to him that 'I really missed you here' whenever for example I see my friends with their boyfriends or their husbands, 'I really feel you and I feel that I need you to be here with me'.... [We would talk about] how we remembered our past times together, like 'Do you remember when we were at ... or when you came home I did this for you. We do a lot of kissing...And he also used a lot of lovely words towards me, actually because his existence really calms me, I mean when I am upset about things or unhappy he used to hug me and be very kind to me... stroking, hugging and kissing me...he tried to do all those things using the video chat I meanIn addition to these calls, May-ling and Ming connect their home locations for long durations of time using Skype. In contrast to Kaitlyn and Tyler's LDR where they are both in the same time zone, May-ling and Ming live 12 hours apart. This dramatic time zone difference plays a large role in how and when May-ling and Ming connect. Even with such a large time difference, they manage to find a way to "hang out" and video directly supports it. In fact, May-ling estimates that about eighty percent of the time, their use of Skype follows the routine described below.

May-ling gets home from work around 6:30 pm, which is 8:30 am in China for Ming and about the time he starts work in the morning. On most days, Ming works from home. Ming knows when May-ling usually arrives home and will send a text message to her around this time to ensure she has arrived home safely. Once he knows she is there, he will call her on Skype. They initiate a video chat session and will then leave it going for the next few hours until May-ling goes to bed. During this time, each continues on with their normal routine. May-ling will cook herself dinner, tidy up the house, read a book, and then get ready for bed. Ming, on the other hand, continues along with his normal work, with the addition that he gets to see May-ling from time to time over the video link. This routine has happened nearly every weekday for the past two years. On weekends, their schedules are not normally as routine so they might or might not connect in this way; it depends if both happen to be at home.

While connected, May-ling will move her laptop around the house depending on what room she is in. This includes the living room, kitchen, bedroom, and even bathroom - when she takes off her makeup, brushes her teeth, and gets ready for bed. Sometimes Ming will even see her getting out of the shower after a 
workout, but this is just "normal" to them and not sexual in nature. Because Ming works from home (and lives alone), there is nobody else around who might happen to see the video link - and thus May-ling — in these compromising situations.

Ming runs Skype on his work computer that sits on a desk at the edge of his living room. Because it is tethered, he cannot move it around the house. He basically sits in front of Skype for most of the time while connected to May-ling. Still, if he gets up from his desk, or ventures to the kitchen, he often rotates the camera to the direction of his new location. Ming also needs to regulate the volume and what is visible on his screen though to match his mixed-context of work and personal life. For example, May-ling describes one particular instance of being connected to Ming:

"Last night I was watching something on TV and he had a meeting and uh he just cut my voice... I could see him and of course the person he was meeting with couldn't see me but I was just, you know, doing my own thing and no sound but we could see each other... his office is in his house. I was minimized so the person with him couldn't see what was happening on the computer. I just look at him once in a while and then he comes back and tells me he is done and I shush him because I am still watching TV."

Once it is bedtime for May-ling, she will move her laptop to her bedroom so that Ming can watch her fall asleep. This is comforting for both of them.

"... I will move [the laptop] to my bedroom, the light is on normally because if I don't turn it on he can't see me... and he normally cuts his voice off so I don't wake up from his phone calls or him talking to people. And at a point in time the computer goes to sleep so it cuts it off....it's on the bedside table and I normally position it towards my face."May-ling and Ming haven't tried using the video link for sexual acts, beyond just kissing. Their view is that the video link does not provide any real form of physical connection. That is, they consider any acts to be solitary explorations and the video link simply provides a view of the other person doing them. May-ling equates this to a pornographic video without any true connection to Ming.

"I've never really had any kind of desire to do virtual sex or anything like that and neither has he, I think...Maybe it's like I'm being watched or something. A lot of times when people ask 'do you have intimate stuff going on online,' I always think to myself that they are talking about a porn movie. I don't want to be in a porn movie for my fiancée."

Taken together, we see that the video link provides an increased feeling of intimacy between the two partners simply by allowing them to have a common sense of "place" and togetherness. Intimacy is not about performing sexual activities together; it is about shared presence. The large geographic and time zone difference means that it is more difficult to participate in shared activities. That is, we don't see May-ling and Ming having dinner together or watching a television 
show like the first case study. Their different time zones and schedules don't really permit such activities. Yet this is not a problem because they can still be a part of each other's lives because of the video link. None of the other technologies that the couple has tried have provided such a rich connection for them.

Like the first case study, May-ling and Ming also face challenges because of the design of the video software and camera. Lighting again is an issue, in particular when May-ling brings her laptop into her bedroom to fall asleep: she needs darkness to fall asleep but Ming needs light to see her. Currently, May-ling compromises. The camera must also be carefully angled in order to capture May-Ling in bed. They use a bedside table but it must be positioned in the correct location, which is not where it normally would be. They've tried placing the laptop right on the bed; however, this made it exceptionally hot and prone to falling over. Audio is again a challenge. In this case, it is because a "work" location transmits to a home location, and the audio must be muted periodically to avoid interruptions and manage the coming and going of work colleagues or clients. Tethering is also a problem - the fixed nature of the desktop computer, power and Internet connectivity, distance limits of the microphone pickup-can anchor people to a specific location, so they cannot move around the home easily. Certainly, all of these challenges again present design opportunities.

\section{Discussion}

Our chapter illustrates how couples in LDRs increase intimacy and maintain their relationships by keeping a video link open for an extended period of time. This creates a shared sense of presence for the couple, even when physically apart. In all our couples, video enhanced the couple's feelings of shared living, shared experiences, and shared intimacy.

The case studies describe a composite of the core routines and communication patterns that participants in our study told us about. Certainly we cannot characterize every couple within two case studies and, indeed, we saw some idiosyncratic differences emerge between couples. For example, some people preferred different shared activities than the television watching that we presented in the first case study. Other couples would listen to music, browse the web or read together (each their own book, but it was still the same activity). Although all our couples had well-defined routines for seeing each other, the frequency and duration of the video connections varied. Some participants would connect every night with their partners, while others would connect several times per week. Nearly all would connect for periods of longer than an hour and most would stay connected from the time they arrived at home after work until bedtime. A small number of partic- 
ipants expressed discomforts about how they looked on the video link, yet the majority did not care about their appearance on camera.

Most couples did have some degree of cybersex, ranging from kissing to nakedness, to flirting, to embracing, to masturbation. However, most did not go that far: one male-male couple reported actively engaging in regular cybersex, while another male-female couple had done it only occasionally. What was common to all our couples was that they described sex - no matter how far they took itentirely as an extension of intimacy. That is, it wasn't so much about the sex, but rather about being together and being intimate together.

Still, nearly all couples expressed similar issues of "awkwardness" in regards to performing hard-core sexual acts over the video link. This ranged from some feeling that it was somehow "wrong," to others just not finding it that satisfying, to others that had didn't pursue it because they were concerned that the video channel wasn't secure, i.e., that an outsider could eavesdrop and even record their sexual act.

There were also participants in our study who fell somewhere in the middle of the two case studies in terms of their geographical distance apart. The first case study explores couples who are in the same time zone and a few hours drive apart, while the second case study looks at connecting across many time zones. A number of our participants were somewhere in-between these ranges, where they were apart by two to three time zones across continental North America. Even in this seemingly small time-zone difference, the difference was still enough to affect the couples' routine. In these situations, shared meal times were not possible. Yet people did find a way to develop routines. Most couples could still connect, and most often did, during the evening. For one partner it was early evening and for the other it was the late evening. This sometimes meant adjusting one's sleep cycle to accommodate the need to have shared "together time."

Overall, our interviews and subsequent case studies reveal a pattern of communication that has moved beyond phone call-like usage. Even when couples conversed, the video added a crucial element of seeing the other person's face and facial expressions. Even more radically, couples have appropriated video technologies in a new way that makes more sense to them: They have turned video chat systems into tools that connect two locations in a more permanent fashion. It isn't so much about conversing as it is about shared living. This usage begins to look dramatically similar to media space systems of the 1980s and onwards that saw industrial research labs and universities (e.g., PARC, EuroPARC, University of Toronto) connect distributed offices, workspaces, and buildings with "alwayson" video (Harrison, 2009). We also see this theme emerge more broadly in this book; the subsequent chapter on "Media Space in the Home" reveals how families with children also find value in leaving their video link open for an extended period of to connect with grandparents. Yet video as used by LDRs is much more than 
sharing a living space with a colleague: significantly, LDRs appropriate the channel as a way to maintain their intimacy and their relationship.

Using a video link in this way is not easy. As noted in our case studies, there are many challenges. Pragmatically, it can be difficult to situate and move a computer, even if it is a laptop, to the various locations that one may wish to broadcast his or her life from to the remote partner. There are also problems related to camera angle, lighting, and audio. While not discussed in our case studies, many participants similarly told us that it was sometimes difficult to keep their video connection going for longer periods of time because of software issues with their video chat system and because of variable performance of the Internet. These are all technical issues that need to be addressed through design and implementation.

In addition, many social issues exist that are perhaps more difficult to solve through design. People are hesitant to broadcast video for extended periods of time from work or they may not be allowed to; this forces connections into the evening hours. Sometimes people can work around this by working from home. Yet this brings challenges with connecting mixed contexts, namely work and home, as seen in the second case study. There are also challenges in moving from shared time together to intimate sexual activities. Currently it is not possible to truly connect with a remote partner in a physical sense when using a video connection because the technology is lacking. Video chat systems are simply not designed with cybersex in mind, akin to the way that sex toys are now being carefully designed for aesthetics, embodied pleasure, and intimate experiences (Bardzell and Bardzell, 2011). This turns a design problem into a social issue where feelings of awkwardness or embarrassment arise when couples try to use a video chat system for sex acts, but are unable to do so.

\section{Conclusion}

Our chapter has explored the ways in which couples in long-distance relationships stay connected by using a video chat system. In particular, we have focused on describing how couples increase intimacy by leaving a video link open for an extended period of time. This has opened up the possibility for couples to share a variety of activities together while apart. It has also enabled couples to connect their residences together such that they can continue on with their normal routines, only now a remote partner can see and even be a part of them in a way that is not possible with other technologies. This suggests an avenue of design that directly supports creating a shared sense of presence between partners in long-distance relationships. This should certainly include systems that utilize a video link, but they may also include other mediums. The crux is finding and utilizing mediums that provide a rich enough experience that partners feel they are actually a part of their remote companion's life. 


\section{References}

1. Aguila, A.P.N. (2009) Living Long Distance Relationships through ComputerMediated Communication Social Science Diliman 5:1-2, 83-106.

2. Bardzell, J., and Bardzell, S. (2011) "Pleasure is Your Birthright": Digitally Enabled Designer Sex Toys as a Case of Third-Wave HCI, Proc. CHI, ACM Press, 257-266.

3. Canary, D., and Stafford, L. (1994) Maintaining Relationships through Strategic and Routine Interactions, In Communication and Relational Maintenance, Edited by Canary, D., and Stafford, L., Academic Press Inc, 3-22.

4. Cooper, A. (1999) The Inmates are Running the Asylum, SAM.

5. Dainton, M., and Aylor, B. (2002) Patterns of communication channel use in the maintenance of long distance relationships, Communication Research Reports, 19, 118-129.

6. Dimmick, J., Kline, S., and Stafford, L. (2000) The gratification niches of personal email and the telephone: Competition, displacement, and complementarity, Communication Research, 27, 227-248.

7. Dindia, K., and Emmers-Sommer, T.M. (2006) What partners do to maintain their close relationships, In Close relationships: Functions, forms and processes, New York: Psychology Press, 305-324.

8. Duck, S. W., (1994) Steady s(he) goes: Relational maintenance as a shared meaning system. In D. J. Canary \& L. Stafford (Eds.), Communication and relational maintenance, San Diego, CA: Academic Press.

9. Grudin, J. and Pruitt, J. (2002) Personas, participatory design and product development: an infrastructure for engagement, Proceedings of the Participatory Design Conference.

10. Harrison, S. (2009) Media Space: 20+ Years of Mediated Life, Springer.

11.Johnson, A.J., Haigh, M., Becker, J., Craig, E., and Wigley, S. (2008) College Students' Use of Relational Management Strategies in Email in Long-Distance and Geographically Close Relationships, Journal of Computer Mediated Communication, 13, 381-404.

12. Kaye, J. (2006) I just clicked to say I love you: rich evaluations of minimal communication, Extended Abstracts of Proc. CHI, ACM Press.

13.Pistole, M.C., Roberts, A., Chapman, M.L. (2010) Attachment, relationship maintenance, and stress in long distance and geographically close romantic relationships, Journal of Social and Personal Relationships, Vol. 27(4), 535552.

14.Pistole, M.C., Roberts, A., Mosko, J. (2010) Commitment Predictors: LongDistance Versus Geographically Close Relationships, Journal of Counseling and Development, Spring 2010, Volume 88, 146-153. 
15. Rheingold, H. (2005) Teledildonics and Beyond. In B. Arthur (ed.) The Postmodern Presence: Readings on Postmodernism in American Culture and Society. Altamira Press, 274:287.

16. Rumbough, T. (2001) The development and maintenance of interpersonal relationships through computer-mediated communication, Communication Research Reports, 18(3), 223-229.

17. Shirazi, A., Alt, F., Schmidt, A., Sarjanoja, A., Hynninen, L., Hakkila, J., and Holleis, P. (2009) Emotion Sharing via Self-Composed Melodies on Mobile Phones Proceedings of Mobile HCI, ACM Press.

18. Stafford, L. (2005) Maintaining Long-Distance and Cross-Residential Relationships, Lawrence Erlbaum.

19. Stafford, L. (2010) Geographic Distance and Communication During Courtship Journal of Communication Research, 37(2), 275-297.

20. Stafford, L., \& Canary, D. J. (1991) Maintenance strategies and romantic relationship type, gender, and relational characteristics, Journal of Social and Personal Relationships, 8, 217-242.

21.Stafford, L., Merolla, A., and Castle, J. (2006) When long-distance dating partners become geographically close, Journal of Social and Personal Relationships, 23 (6), 901-919.

22. Stafford, L., and Reske, J. (1990) Idealization and Communication in Long Distance Premarital Relationships, Journal of Family Relations, 39 (3), 274279.

23. Vangelisti, A., and Huston, T. (1994) Maintaining Marital Satisfaction and Love, In Communication and Relational Maintenance, Academic Press Inc, 165-186. 